story in many parts of the country: empty beds that would have been unthinkable just a few weeks ago when Ebola treatment centres were overflowing. Nationally, the growth in the numbers of those infected in Liberia, the worst-affected country, is no longer exponential but has flattened off.

The epidemic has also stabilized in Guinea. But a resurgence of cases in Sierra Leone is a timely reminder that until Ebola is eliminated throughout West Africa, it remains a major threat. As of 18 November, Ebola has infected at least 15,000 people and killed 5,440 of them in these three main affected countries. But the worst-case scenarios predicted by mathematical modellers, which projected a steady apocalyptic rise in Ebola case numbers, have proved far off the mark (see Nature 515, 18; 2014).

Although complacency is as unwise as it is hopefully unlikely - a lull in Ebola cases in the spring prompted authorities to drop their guard, only to see the virus return with a vengeance - there are reasons to believe that the current lull in Liberia and Guinea may continue. And that offers an opportunity to roll back the epidemic at last.

The exact causes of the lull are unclear. Belated international Ebola control efforts are only now beginning to kick in, and have no doubt contributed. But much of the slowdown is perhaps due to Africans themselves coming to terms with the epidemic and blocking its main routes of transmission. In particular, there has been a reduction in traditional burial practices, which are a key source of spread.

The slowing of new cases in Liberia and Guinea is a welcome reprieve for the health-care workers and scientists who have toiled to control a virus that for months has held the advantage. It is an opportunity to regroup, to consolidate gains, and to go all the more on the offensive.

Until recently, MSF, based in Geneva, Switzerland, was the only serious international presence fighting Ebola on the ground, but logistics meant that it could operate only a few large centralized treatment centres. These large centres, often with hundreds of beds, are still needed to absorb any resurgence, particularly in urban areas. But having only large centres is not ideal. Patients often have to travel for many hours or even days to reach them, and by the time they make it are often beyond recovery. They are also likely to have contaminated others en route, so fuelling the spread of the virus.

With its caseloads falling in recent weeks, MSF is coming out of the trenches and taking the fight to the virus, sending mobile teams and smaller treatment centres to the sites of new outbreaks to try to nip "Those them in the bud. MSF sensibly wants other responding to aid groups to adapt in a similar way. It will be a challenge for the more bureaucratic UN must not drop their guard." Mission for Ebola Emergency Response, and the US and other national Ebola-treatment efforts, to quickly change their plans, because they are mainly based around large centres. But it is crucial that the response to Ebola is flexible in the face of the shifting epidemiology.

The slowdown is also buying precious time for the testing of drugs and vaccines: clinical trials of vaccines in particular are being fast-tracked, with the first results due at the end of 2014. Unfortunately, however, drugs and vaccines have captured the spotlight and resources, while more mundane interventions that could have an immediate impact have been neglected. Better rehydration and electrolyte control can dramatically reduce mortality: the case fatality rate for patients treated in rich countries has been a fraction of the $70 \%$ seen in West Africa. Testing convalescent blood and serum from survivors - a potentially gamechanging treatment - should also be a priority.

At the start of October, the United Nations and the World Health Organization set quantitative targets for safe burials, contact tracing and other key public-health control measures, which the international community was to meet by 1 December. It is already obvious that most of these targets will not be met. The breathing space offered by the current lull in Liberia and Guinea offers an opportunity to fill gaps and ramp up coverage of countermeasures. It must not be wasted.

\section{Moon on a stick}

\section{A crowdfunded lunar mission might seem like a long shot - but there is no harm in trying.}

$\mathrm{T}$ The crowdfunding platform Kickstarter is popular with inventors of fashionable bike helmets, hover boards and even a smart frying pan that tells you when to flip a steak. But last week the site that has funded thousands of films, games and gadgets launched a funding effort for something much bigger: a mission to the Moon.

On 19 November, under the banner of 'Lunar Mission One', a UK-led consortium announced a goal to put a lander on the Moon by 2024 and to retrieve and analyse samples from 100 metres below the lunar south pole. The mission itself would cost around US $\$ 1$ billion. For starters, it needs $\$ 1$ million by 17 December. As Nature went to press, it has more than half of that.

Attempting to invert the fund-raising model for science missions, the project would get its cash by encouraging many thousands of people to give a few dollars. In return, investors get the chance to preserve a little bit of themselves in a time capsule that will fill the borehole: either in a digital form, in a 'memory box', or with a strand of hair. The latter would cost as little as $\$ 80$.

This is not the first science project to seek crowdfunding. For example, last year, synthetic biologist Omri Amirav-Drory, founder of the company Genome Compiler, raised $\$ 480,000$ on Kickstarter to create glowing plants. Nor is it the first private venture to shoot for the Moon - the companies that compete for the Google Lunar $\mathrm{X}$ Prize are the most notable.
So how seriously should we take the new Moon shot? Certainly the institutions involved are solid enough. University College London and RAL Space, part of the UK Science and Technology Facilities Council and a partner in more than 200 space missions, have assessed the feasibility of the mission. The Open University in Milton Keynes, UK, is working on the educational side. High-profile celebrity scientists and former UK science ministers have clamoured to back the venture, and seasoned academics from universities across the United Kingdom have built the mission's science case.

The promised science is interesting. Europe has never sent a lander to the lunar surface, and no nation has ever visited its south pole. Permanently shadowed craters there are thought to contain water, and digging deep into the surface could answer countless unsolved questions about the Moon's history. And the timing is good. Space science is basking in the glow of ESA's Rosetta mission, which landed a probe on a comet earlier this month.

But $\$ 1$ billion? Organizers aim to fill a gap in public funding in a way that neither detracts from existing space missions nor puts governments in a predicament. The mission gets funding only if people care enough to contribute, says Richard Holdaway, director of RAL Space. "It's not about deciding whether to spend money on a space programme or a new hospital," he says. "It's democracy at its greatest level."

Perhaps wary of pouring cold water on an aspirational and ambitious plan, sceptics have been surprisingly hard to find. The effort is plainly ambitious. But, the message seems to be, where $\rightarrow$ NATURE.COM To comment online, click on Editorials at: go.nature.com/xhunqv is the harm in trying? If Lunar Mission One misses its funding target, the programme simply stops, having broken the first rule of any sales effort - offer a product that enough consumers want. $\mathrm{m}$ 